\title{
THE MANAGEMENT OF SOCIAL PROBLEMS TALK IN A SUPPORT
} GROUP

\author{
O MANEJO DE CONVERSAS SOBRE PROBLEMAS SOCIAIS EM UM GRUPO \\ $D E A P O I O$
}

Andrezza Gomes Peretti, Pedro Pablo Sampaio Martins and Carla Guanaes-Lorenzi

University of São Paulo, Ribeirão Preto/SP, Brazil

\begin{abstract}
The comprehension of the health-disease process from a multifactorial perspective has allowed important transformations in the healthcare practices. In this article, we discuss the use of the support group as a resource for mental health care, analyzing how conversations about social issues are managed in this context. Based on contributions from the social constructionist movement, we analyzed the transcripts of the conversations developed in meetings of a support group offered to patients of a mental health outpatient clinic. The analysis of the process of meaning making indicates that the discourse of the social influence on mental health is not legitimized, due to a predominant individualistic discourse, which psychologizes care and is centered on the emotional analysis of the problems of the quotidian. We argue that this mode of management brings limits to the construction of the group as a device for promoting autonomy and encouraging the social transformation processes.
\end{abstract}

Keywords: social constructionism; mental health; support groups; social determinants of health.

\section{RESUMO}

A compreensão do processo saúde-doença a partir de uma perspectiva multifatorial tem permitido importantes transformações nas práticas de saúde. Neste artigo, discutimos o uso do grupo de apoio como um recurso para os cuidados de saúde mental, analisando como as conversas sobre as questões sociais são manejadas neste contexto. Com base nas contribuições do movimento construcionista social, analisou as transcrições das conversas desenvolvidas nas reuniões de um grupo de apoio oferecido aos pacientes de um ambulatório de saúde mental. A análise do processo de construção de significado indica que o discurso da influência social sobre a saúde mental não é legitimado, devido a um discurso individualista predominante, que psicologiza cuidado e é centrado na análise emocional dos problemas do cotidiano. Argumenta-se que este modo de manejo traz limites para a construção do grupo como um dispositivo para promover a autonomia e incentivar os processos de transformação social.

Palavras-chave: construcionismo social; saúde mental; grupos de apoio; determinantes sociais da saúde.

\section{Introduction}

The practice of group therapy as healthcare began to be developed at the beginning of the twentieth century. By bringing together inpatients with common problems, the aim was to reduce treatment costs and provide guidance on how to deal with the disease/ mental disorder. This practice increased after World War II, as the social changes resulting from this period raised reflections on the importance of psychological treatment for people who had suffered trauma, and the need to assist them in their return to social life and the labor market. This model, used especially as a space for exchanging experiences, also began to be developed in diverse hospitalization scenarios, due to the recognition by professionals that patients obtained significant improvements when sharing common experiences (Scheidlinger, 1994).

With the end of the war and the advent of the psychiatric reform, investments were made in the search for spaces where people were cared for at liberty (Guedes et al., 2010), and in the construction of policies that sought to maintain patients within the community. However, there was a shortage of trained professionals for this and the therapeutic groups also started to be seen as an economic resource, favoring the care of more people in less time (Bechelli \& Santos, 2004). With the increase in scientific interest regarding 
therapeutic groups, they began to be analyzed in terms of their specificities, highlighting the particular aims of this setting and differentiating them from individual treatment approaches (Scheidlinger, 1994).

Specifically, support groups began to be used as tools for care in different contexts and later spread as resources for healthcare (Guanaes \& Japur, 2001). As summarized by Schopler and Galinsky (1993), the proliferation of these groups is related to the growing need for support determined by the rapid social changes, which increased the experience of stressful situations. Thus, this type of group seeks to help people to face difficult emotional situations and to cope with quotidian stresses, moments of life transition and economic problems. Generally, they have a limited duration (Klein, 1993), valuing the exchange of experiences and seeking the relief of symptoms through non-interpretive therapeutic management, focusing on the acceptance, the support and the offer of guidance (Guanaes \& Japur, 2001).

The scientific literature of the area highlights different features in the formation of therapeutic groups (Guimarães \& Contel, 2009; Scheidlinger, 1994). Some studies approach specific theories and techniques, such as psychoanalysis (Campos, Campos, \& Rosa, 2010) and cognitive behavioral therapy (Habigzang, Hatzenberger, Corte, Stroeher, \& Koller, 2006), while others explore the meanings constructed by the patient about the problem that led them to group therapy and their process of change (Carrijo \& Rasera, 2010). However, authors highlight how the therapeutic groups, in diverse theoretical approaches, offer comfort to the patients, who no longer feel like the only ones with a problem (Yalom \& Leszcz, 2005) and may also construct new descriptions of themselves (Carrijo \& Rasera, 2010).

In the mental health context, therapeutic groups can be constructed as spaces for the discussion of the expectations for improvement, society's prejudice about mental illness, the characteristics of the treatment and the construction of interpersonal relationships. As Guimarães and Contel (2009) conclude, therapeutic groups allow patients to develop a critical stance faced with the descriptions of disorder and the way society assists them. This discussion draws attention, first, to the possible social action resulting from the group and, secondly, to the multiple issues involved in the production of mental healthcare.

Analyzing critically the productions about group and group process throughout the twentieth century, we agree with Barros (2007) that the group is often discursively constructed as an "intermediary" between the individual and society. This conception invites to the analysis of the effects of this dichotomy. There are a variety of explanatory theories about the groups, in which they are sometimes described in terms of essential and universal processes, and sometimes in terms of their dynamism and plurality. An example of this dichotomy is the construction of the group at times as a space for social rehabilitation and, at other times, as a device that moves social and political transformations, thus, as a creative space for the construction of autonomy and empowerment.

Sensitive to these reflections, we have adopted in this article, the concept of group as a social construction (Rasera \& Japur, 2007), thus moving away from universalizing and essentialist concepts on the theme. We understand the group as a discursive practice that gains meaning as the people, in specific socio-historical contexts, locations and situations, actively produce descriptions of group and its process. Thus, our interest is in the communicative and relational process that constructs the group as a possibility at every interactive moment (Guanaes, 2006) and may therefore promote both therapeutic and non-therapeutic factors; functioning as an adaptive resource or as a device for critical reflection, promoting autonomy and change. From this perspective, we do not adopt a priori discourse that defends the group as being a reality in itself and, therefore, primarily a tool for change. Instead, we focus on the different ways in which people, in their meetings, jointly construct meaning about the world around them, and on how these meanings may have different implications and effects for the construction of the group itself, and overall for the construction of personal and social worlds.

\section{The influence of social factors on health/ mental health: challenges to the individualist discourse}

The development of public health programs has undergone major changes since, in 1946, the World Health Organization (WHO) defined health positively, considering it as a state of physical, mental and social well-being (Grad, 2002). This first definition spurred a critical movement regarding the current biomedical model at the time, emphasizing a comprehensive view of the person, seen in a context of multiple determinations. This definition shows how the concepts of health and disease are not static, as well as the socio-historical contingencies present in their determination (Badziak \& Moura, 2010).

The notion of social determinants of health (SDH) combined with this movement of amplification 
of the comprehension of health and its practices. According to the World Health Organization, the SDH refer to "the conditions in which people are born, grow, live, work and age, including the health system". This perspective includes attention to how power, money and resources are distributed at different levels (global, national and local), with these determinants largely responsible for health inequities, internal to each country and between different countries. Therefore, the notion of SDH is wide, allowing us to focus both on the concrete conditions of the life context (housing, sanitation, nutrition, physical and environmental resources, working conditions, employment, transportation, drug addiction, etc.), as well as gender relationships, power, status and processes of social exclusion. Furthermore, this notion is broadly sensitive to the social and cultural differences that traverse the analysis of the living and health conditions of people, highlighting the understanding that the ways of caring and reaching different communities differ from culture to culture (http://www.who.int/social_determinants/en/).

In an article outlining the objectives of the Commission on Social Determinants of Health (CSDH), Marmot (2005) highlights that the SDH function as important health indicators and that actions related to them are fundamental. For the author,

if the major determinants of health are social, so must be the remedies. Treating existing disease is urgent and will always receive high priority but should not be to the exclusion of taking action on the underlying social determinants of health. (p. 110)

Specifically in relation to mental illness, studies refer to its multifactorial etiology, and point out, more particularly, its possible relationships with social and economic factors. Regarding depression, for example, Patel et al. (2010) highlight that "there are significantly increased rates of depression among low socioeconomic groups, and exposure to risk factors is disproportionately high in contexts characterized by social disadvantage where vulnerable groups are overrepresented" (p. 129).

In the Brazilian context, Ludermir (2008) discusses the influence of class and gender issues on the mental health of people, and Alves and Rodrigues (2010) discuss the influence of social factors such as urbanization, family relationships, culture, social exclusion and stigma. However, according to Ludermir (2008), the social aspects tend not to be recognized in the contexts of health and often the professionals do not accept these problems due to lack of guidance and recognition of their importance. In the same vein, Alves and Rodrigues (2010) consider that to know what the social problems of a given population are helps to think about the need for prevention and mental health care policies. As Pinheiro, Santos and Santos (2009) highlight, the collective discourses about the quotidian, family and also about difficulties such as violence, unemployment, the economy and other social issues are connected with psychic suffering, however, can only be described by those who experience the link between these factors and their mental health, as each community responds differently faced with such influences.

In a critical and reflective analysis of the notion of SDH, Zioni and Westphal (2007) highlight that the inclusion of the social dimension in the analysis of the health and disease process invites a repoliticization of the health field, bringing theoretical and ethical challenges. Supported by an analysis that indicates the important paradigm shifts in the comprehension of health, the authors conclude that "in the contemporaneity the social issue does not concern the promotion of an abstract citizenship, but rather the creation of spaces where the citizenry can be rooted in individual concrete experiences" (p.33).

This expanded vision of health brings major challenges to modern psychology (Gergen, 1997), as a psychologizing discourse still predominates in this field, marked by the influence of the individualist discourse of care (McNamee, 2002). Traditionally, in this field, the problems tend to be understood as centered on the person, at the expense of a historically and culturally contextualized comprehension that is also sensitive to the influence of social factors on health. We see, for example, that in this field it is common that diagnoses are used to categorize people, taking the individual as the sole agent of action in their life (Gergen, Hoffman, \& Anderson, 1996). This psychological tradition has been questioned by authors who point out, as an alternative to the discourse of a self-contained individual, a dialogic and relational view of the person (Gergen, 2009; Sampson, 1993).

\section{Justification and aim}

Guanaes and Japur (2005), in a previous study about a support group in mental health, described diverse meanings constructed in the group interaction regarding mental disorders. One of these meanings pointed to social problems as having influence on the disorder. Continuing this study, we explore the possibilities of change engendered in the group process from the negotiation of meanings about social problems among the participants. 
Thus, considering: (a) the changes in world health policies and discourses, which seek to better comprehend the social determinants of the health of the patients to meet demands for care; (b) the search for mental health practices that valorize the social coexistence; (c) therapeutic groups as important resources for treatment in the context of mental health; this article aims to describe how the therapeutic management of conversations about social problems takes place in the context of a support group for patients in an outpatient mental health clinic and describes the implications of this management for the intervention possibilities constructed in the group. We hope, with this, to contribute to the reflection regarding socially committed therapeutic practices that address mental health care as an amplified concept.

\section{Method}

\section{Theoretical-methodological framework}

This study was developed based on the contributions of the social constructionist movement in psychology, which understands knowledge as a product of human participation in traditions, situated in specific social and historical contexts (Gergen, 1997). This perspective comprehends knowledge as social action, constructed in relational spaces of meaning making, dependent on constant negotiation processes and generating pragmatic effects on the possibilities of constructing the social world where it was produced (McNamee \& Hosking, 2011). We designed this study based on the recognition of the centrality of this process of meaning making in the organization of forms of social life. Thus, we prioritized the analysis of the group focusing on the discursive practices between its participants.

\section{Context and Participants}

We analyzed information from a database, constructed from the recording of 16 sessions of a support group offered to patients at a mental health outpatient clinic, part of a public healthcare service located in a medium-sized municipality in the state of São Paulo, Brazil. The group was coordinated by a psychiatric physician and observed by the third author of this article. Altogether 8 women and 2 men, aged 29 to 65 years, participated in this group. The majority of these people had incomplete elementary education, worked in domestic service, were married, had no history of psychiatric hospitalization, and made use of anxiolytics and/or antidepressants. The main complaints that motivated the search for treatment in the service included depression, anxiety and relationship difficulties. Information from the medical records indicated that the patients were experiencing, at the time of referral, a crisis situation in a life history marked by difficulties and psychosocial adaptation problems (Guanaes \& Japur, 2001).

The research project from which the database was constructed was previously approved by the Research Ethics Committee. In this article, the names of the participants of the group have been modified in order to prevent their identification. All the participants agreed to participate in the study, and signed the Terms of Free Prior Informed Consent.

\section{Procedures of constitution and analysis of the research corpus}

The research corpus was constructed from the audio recording and literal transcription of the 16 sessions of the previously mentioned group. As already mentioned, we rely primarily on the analysis made by Guanaes and Japur (2005), who described meanings negotiated by the participants of this group about mental illness, and we analyze some of their implications. From the proposal of these authors, we specifically selected for analysis of the process of meaning making the category described by them as "mental illness as a result of social problems", since, in the preliminary analysis of the interactive process of the group, we were especially struck (Shotter \& Katz, 1996) by the way the management of these conversations in this context was performed.

From this choice, we proceeded to the following analysis steps: 1) we selected all the moments in which "social issues" appeared in the conversations among the participants of the group, based on the notion of SDH proposed by the World Health Organization (Marmot, 2005); 2) We then named categories that allowed us to visualize these social issues which were discussed in the group context in a way associated with the view of the problem/mental illness; 3) next, we observed how both the patients and the therapists interacted through the emergence of these topics, i.e., we sought to consider the interactive process triggered in the group by the emergency of these themes, considering that this would allow us to describe how the therapeutic management of the conversations about social issues was carried out; and 4) finally, we selected, for presentation in this article, the moments in which there was greater interaction of the participants in the conversation, at the expense of moments in which participants only cited or made reference to social issues without taking the centrality of the dialogues developed in the group. 


\section{Results and discussion}

From the analysis of the set of therapeutic meetings of this support group, we observed that the participants resorted, at different moments of their interaction, to the argument that social factors could be responsible for the problem that led to the treatment in the mental health outpatient clinic. The categories we constructed to give visibility to these social themes frequently negotiated by the participants were: (a) Violence: covering urban violence, such as assaults and robberies, homicides, and domestic violence, suffered both by the participants themselves as well as people close to them; (b) Employment and financial difficulties: low family income, financial difficulties, unemployment and job dissatisfaction; (c) Gender relations: depreciation of the feminine in relation to the masculine, describing relationships guided by a submission of the woman in relation to the man and by well-defined roles that limit some choices in the lives of the participants; and (d) Drug abuse: stories regarding the abuse of psychoactive substances such as alcohol and other drugs, usually illegal, by family members of the participants of the group.

The analysis of the conversations around these issues led us to the conclusion that these were managed in ways that do not legitimize them as important subjects relevant to the group context. In most cases, these interactions were based on an individualistic psychological discourse (McNamee, 2002), that comprehends problem and change as emotional, subjective and individual to the people.

The management of social problems talk as not being legitimate for this group context produced pragmatic effects that were important for their development. Firstly, this management favored the construction of a clear distinction between biological, emotional and social aspects around the mental health of the patient, constructing the group as a space to deal only with emotional issues. This description, taken as reference for the group, often disregarded explanations brought by patients themselves about their problems and possible solutions for them. Consequently, this has limited the possibility of constructing a critical discourse, which could be potentially useful for the enhancement of these people as autonomous citizens with rights. To emphasize these conclusions and to demonstrate the path that led us to them, we next present the analysis of some passages of dialogue developed in this support group.
In this city, really, it's difficult to live...

At the beginning of the $3^{\text {rd }}$ session, the group participants discussed financial and employment difficulties, pointing out how they affect their mental health. Roberta said that her husband had been feeling very jealous of her and it made her ill. Her speech began as a dialogue on how nervousness unbalances even the physical health of people. Next, Valter and Marli talked about urban dangers, underscoring the difficulties of living with assaults and robberies in their quotidian lives, showing concern for their own safety and that of their families. However, the therapist did not stimulate the development of this conversation, proposing the return to the previous issue regarding the jealousy of the husband of Roberta.

Valter: Now one important detail: [in this city], really, it's difficult to live... If only I could live in a very small town, a calmer city, I would like a little more peace. Maybe I would have other problems, but it would be better, because the life we're leading in [name of the city] - it's hectic, violent.

Marli: The schools are such a mess, right? My god!

Valter: All kinds of things, right? I was assaulted twice, they already stole two motorbikes, another time they robbed me...

Marli: My son is also paying for a bike that was stolen from him...

Valter: So I would like to say, we are convinced that we need to have a bit more of security ... My son goes out at night, or goes to his girlfriend's house, or wants to do something, go out on his motorcycle, we get worried ...

Marli: Did you hear that story yesterday, about the man who set fire to the four children, who burned the apartment, five burned... the woman in the hospital, all four burned to death? ...

Therapist: But look, I think our conversation about what was happening with the crises of Roberta took a turn towards something beyond our control, because we cannot do anything within our group about the violence that's there outside...

Marli: But that's what makes us ill!

Therapist: I don't know if it is that... like the story she told. Could it be the jealousy that's making her sick?... (Session 3, p.27, L. 33 - p.30, L. 3)

In this excerpt, the participants were talking about who have experienced similar situations, 
agreeing about the negative influence of these issues in their lives. In the initial management of this conversation, Marli and Valter constructed a link between the difficult life in the city and their mental health - "But that's what makes us". However, when the therapist stepped in the interaction, three important things happened. First, he actively deconstructed this theme as legitimate for that group, when stating that the conversation "took a turn towards something beyond our control". Secondly, over the protest of Marli - who explained that the conversation was under control, considering that those themes were related to the health of the patients - the therapist continued to create a distinction between the urban violence (social factor) and the jealousy (individual factor), favoring the individual explanation as that responsible for the disorder and as something possible to be worked within the group process. Finally, the speech of the therapist redirected the topic of group interaction toward the emotional issue of Roberta, instead of the social influences on the health of patients.

On the one hand, this intervention of the therapist demonstrates his insertion into a psychological individualist tradition that, according McNamee (2002), searches for key aspects of the individual, locating the causes of their suffering in internal processes and, consequently, attributing individual responsibility for the problem and for the change. Analyzed within the logic promoted by this individualist discourse, the speech of the therapist in the selected extracts makes sense: since the origin of the suffering is within Roberta - her jealousy - a conversation about urban violence becomes a diversion from the subject which the group should address.

Clearly, the speech of the therapist is not, in itself, sufficient to determine the meaning about the conversation, since the meaning is constructed in the supplementary actions between the interlocutors (Gergen, 1997). Marli even opposed the proposition that to talk about violence was deviating from the subject. However, not all voices in an interaction have the same influence. Between the therapist's insistence that the jealousy of Roberta should be the topic of conversation and the responses of the other patients, who continued the conversation in this direction, the speech of the therapist was legitimized, constructing the group as a space for discussion and exploration of emotional issues, rather than for analysis of social problems. This generated important implications. An interactive moment that could have been used for questioning and critical reflection on the urban social context in which these patients live and, consequently, to explore resources (individual and collective) to avoid suffering related to violence in their community, ended up being used as a conversation of individual pathologization (McNamee, 2002). The understanding that people in this group showed few internal resources to adequately confront these social situations seemed to prevail. In addition, this discussion highlights the effects of the hierarchical posture assumed by the therapist, who, to guide the conversation in the "right direction", was not responsive (Shotter \& Katz, 1996) to the need presented by the group at that moment.

Interestingly, this posture, initially adopted only by the therapist, began to be used also by the members of the group themselves - which clearly illustrates how the construction of knowledge is carried out in the processes of social interaction. As described by McNamee \& Hosking (2011), it is in the coordination of actions that meanings are jointly supported and that patterns and rituals emerge, as well as expectations, values and traditions. Thus, as we explore below, the possible influence of social factors on the healthdisease process started to also be rejected as a possible explanation for their mental health problems by the participants themselves.

\section{The problem is having to live with that money...}

In the $10^{\text {th }}$ session, the influence of social factors on mental health appeared again, this time with references by the patients about work and financial difficulties. In a moment of widespread interaction among the participants, they complained of low wages and questioned the participation of the government in changing the living conditions of the people. The therapist participated in the conversation again, this time confronting the movement of the participants to attribute the responsibility for their problems to the government. Despite the effort of Rosilene to legitimize her explanation, a new meaning began to predominate in the group interaction, a meaning that favors the analysis of the participation of the "emotional" side and the maintenance of the individual problem.

Therapist: But look, you are in a dilemma, right? If you work less, your income will decrease, and you may not be able to help to pay the bills. But then, when are you going to start taking care of your life?

Rosilene: But the problem is having to live with [the amount of salary], the government have to be shown that you cannot not live with this.

Therapist: Ah, so the problem is the government...

Rosilene: Of course!

Therapist: It is no longer the children?! [ironically] 
Rosilene: $99.9 \%$ is the government's fault yes. Tell me, doctor, tell me, could one of those men manage to live for at least a day with this money? ...

Therapist: But you recognize? Maybe life is the way it is, as you have said here, due to some need that you have, and it seems to me that this need is emotional. You said it was the need to earn money, but is it just that? And all my attempts to bring our conversation to the emotional side were rejected. This group does not want to talk about feelings!

Marli: But the emotional that you speak about, what is that? ... [group laughter]

Therapist: What is the emotional?

Marli: Yes...

Therapist: What do you think?

Marli: No, I asked the question! [laughter]

Therapist: Am I happy or am I sad?

Marli: Ah, you're smiling unintentionally! [laughter]

Therapist: OK! Look at this that is emotional, and you ask me what it is? Don't you know what is emotional?

Marli: Yeah, but I said, what has the emotional to do with our work, right? That's why I asked the question. You said that we cannot talk about our work, that we have to talk about the emotional. Because in our work we have to have emotion for our work, isn't that it?

Therapist: I didn't say that you cannot talk about the work... ...

Valter: But the problem is that we are unable to distinguish our emotional part. Perhaps we have no reasons to blame a particular work or a particular thing that we do not want to do... (Session 10, p.15, L.11 - p.25, L.13)

This extract also illustrates a moment of great interaction among the participants, suggesting a certain effort to explain the influence of social factors (such as money, work and employment) on their mental health. This is a reasonable conclusion if we consider, for example, the study by Alves and Rodrigues (2010) that relates job dissatisfaction with low self-esteem, despair and concern over the shortage of essential goods, such as food. Furthermore, according to the guidelines of the $\mathrm{CSDH}$, to explore the quotidian and economic conditions of patients may be a way of seeking more appropriate treatment resources, because these conditions are situated in a local culture that is often different from that of the healthcare professional.
However, as in the preceding discussion, the therapist actively proposed that this type of explanation should not be the focus of the conversations within the group. Both Roberta and Marli questioned this posture of the therapist, the latter seeking to comprehend what the emotional aspect is to which the therapist refers, and pointing out the impossibility of separating it from the social issues they experience in the quotidian. In the development of this dialogue, Valter entered the discussion contributing to the explanation of the therapist that to talk about financial difficulties might be diverting from the issues which they really should address: their emotional difficulties. After this moment, the conversation was directed toward the emotional difficulties each one had in coping with the problems of quotidian life. Therefore, once again, the management of the conversation did not legitimize the social issue as important to be discussed in the group and thus prevented the construction of other proposals of help - for example, commitments to the construction of empowerment processes and social mobilization possibilities. The discourse of individual responsibility for the problem is also evident in the following extract, in which the theme of inequality in gender relations enters into negotiation in the group context.

\section{So it's not a disorder, it's adultery...}

In the $13^{\text {th }}$ session, Roberta reported that she felt bad that day, as she had told her husband that she did not love him anymore. She hoped the group would help her to feel sexual desire for him again. Marli wondered if she was thinking of someone else and Roberta said yes. Ana Maria then spoke about changes common throughout the marriage, noting that Roberta could still love her husband, although this was manifested in a different way now. Marli, in turn, said that Roberta was not ill: what she had was a case of adultery and an urge to meet with another man. From there, other participants entered the dialogue, contributing to the initial explanation proposed by Marli and accentuating a moral discourse about what is expected of a married woman.

Roberta: Maybe my feelings for him will come back, with time, you know, until I finish my treatment, right?

Therapist: You can go back to liking him....

Marli: Did you stop only the sexual life or did you stop loving him, everything, everything? Everything?

Roberta: I no longer feel the love I felt before, but there are the time he wants sex with me...

Marli: And do you think about another man? 
Roberta: No. I've thought, I've had, and with my problems I stopped this. Marli: Already, right, have you thought about someone
else to live with you?

Roberta: Yes, it's just that...

Marli: Do you think that you stopped thinking that, but you did not? It looks like you have not stopped, because you're stopping to love him, then that little root will grow... It is dangerous.

Roberta: This person I had already forgotten, but I'm always close to him, I'm always seeing him. So I keep thinking. ... Except that when I see him, you know, I want to talk. Only I know that if I talk to him, I am afraid of everything increasing, at that time I will already start to like that person...

Marli: So it is not a disorder, it is adultery. ... (Session 13, p. 16, L.8 - p.17, L.26)

In the explanations constructed in this dialogue, we observe, on one hand, the strength of the discourse of mental illness as social and, on the other, the emergence of a language shared by the group that clearly separated what the disorder is - an individually experienced aspect - from what it is not - in this case, the amorous conflict of Roberta. Thus, the participants did not regard the suffering described by Roberta and did not legitimize it as a significant problem, after all her problem was not a disorder but adultery. Again this type of separation between mental health as an individual or social product, negotiated in the management of the group discussion, limited the therapeutic possibilities of the group in that moment. The conversation caused a moral judgment regarding the behavior of Roberta, who should preserve her marriage. To describe the situation of Roberta in that way implied the exclusion from the interaction of a discussion of gender that could perhaps have been useful for comprehending her situation: what social demands arise for a married woman with children, who wants to live another kind of experience? How can this type of social discourse be constituted as a health problem for a woman inserted in a moral order that clearly defines the expectations in relation to the role of "mother of a family"?

In this way, some authors have observed that cases of depression and anxiety are more common in women, and attribute this to the fact that, generally in the Western urban societies, women have less power to control their lives and receive less value for their activities, leaving them more vulnerable to violence (Alves \& Rodrigues, 2010; Lurdermir, 2008). Despite this, to construct the group as a space that is limited to the exploration of emotions only restricts the discussion about these issues and places in Roberta and in her internal and emotional processes the responsibility for her suffering. Thus, the discourse marked by a well-defined female social role was stronger than the possibility of exploring alternative actions for Roberta.

\section{Final considerations}

The analysis of the meetings of this support group in a mental health outpatient clinic has allowed us to realize that, despite the diverse possibilities of meanings constructed for mental illness in the group, not all of these meanings were legitimized as issues pertaining to this context of support. Analyzing specifically the management of the conversations that related aspects of the social life of the participants to their mental health, we realized how this theme, in the flow of the conversation, was devalued, initially by the therapist and, over time, also by the group participants themselves. The participation of the therapist in these interactions assumed special relevance as he sought to redirect the conversation of the group to what he regarded as a legitimate subject, which he called "emotional".

We discussed how this understanding by the therapist is anchored in an individualistic perspective of psychological knowledge (McNamee, 2002) and how the management of these issues ultimately limits the possibility of the support group becoming a space of social, ethical and political questioning. We are not proposing here a stance that favors one or other understanding regarding which social issues should be explored or how to approach them (the specific political positions with which participants or therapists are committed). However, it is worth remembering that to choose not to talk about social issues is also a political and ideological position that, as our analysis highlighted, has implications. Since there is no possibility of a political neutral space, the invitation is to clarify which of these positions are present, how they influence the conversation and how they can be useful or not for its development (Gergen, 1997).

In this sense, we believe that a focus on the process of conversation that is both socially committed as well as responsive to the descriptions brought by patients about their own mental health may invite reflection on their inclusion in a social and historical context, and on the ways in which it can positively or negatively affect their health. Thus, our interest is to expand the types of action that become possible from the interaction of the group, whether by the 
valorization of the exploration of collective resources to deal with these situations, or by the valorization of the individual and subjective reflection regarding their choices, feelings and ways of life. Moreover, there is the possibility, from the knowledge of the social difficulties that patients experience, to assist public institutions to think about policies that take care of the community in a manner more consistent with its needs (Marmot, 2005).

We therefore propose an amplification of the possibilities of interaction and care in the group. We do not seek to construct causal relationships that simply substitute biological or psychological determinants for social determinants as the causes of mental suffering. We propose, instead, to leave the deterministic logic, considering these explanations as discourses that, in use, invite certain effects and implications. To comprehend biological, psychological or social influences within this discourse frame is a way of valorizing the changes that have been historically produced in the concepts of health. The proposal is for a change in the logic of mental health care, so that we seek to go beyond a tradition that considers the function of the treatment as either care of the biological body through medication; or as care "of the emotional" through diverse therapies (including that of group) - as if this emotional was detached from the social contexts in which it is produced.

Accordingly, we believe that this study can contribute to the reflection on the group as a mental health care device, indicating other possible applications for this type of practice - which is consonant with the reflection on the importance of transformations in the healthcare practices, in the direction of an expanded clinic, sensitive to the complexity of the factors that take part of our healthcare processes. Conceived as a relational and dialogic process, the group indicates unpredictable possibilities, flexible and powerful resource for the resumption of the centrality of interpersonal relationships in health promotion and human development.

\section{References}

Alves, A. A. M. \& Rodrigues, N. F. (2010). Determinantes sociais e econômicos da saúde mental. Revista Portuguesa de Saúde Pública, 28(2), 127-131.

Badziak, R. P. F. \& Moura, V. E. V. (2010). Determinantes sociais da saúde: um conceito para efetivação do direito à saúde. Revista de Saúde Pública de Santa Catarina, 3(1), 69-79.

Barros, R. B. (2007). Grupo: a afirmação de um simulacro. Porto Alegre: Sulina.

Bechelli, L. P. \& Santos, M. A. (2004). Psicoterapia de grupo: como surgiu e evoluiu. Revista Latino-Americana de Enfermagem, 12(2), 242-249.
Campos, D. T. F., Campos, T. H. F., \& Rosa, C. M. (2010). A confusão de línguas e os desafios da psicanálise de grupo em instituição. Psicologia: Ciência e Profissão, 30(3), 504-523.

Carrijo, R. S. \& Rasera, E. F. (2010). Mudança em psicoterapia de grupo: reflexões a partir da terapia narrativa. Psicologia Clínica, 22(1), 125-140.

Gergen, K. J. (2009). Relational being : Beyond self and community. Oxford, New York: Oxford University Press.

Gergen, K.J. (1997). Realities and relationships: Soudings in social construction.Cambridge: Harvard University Press.

Gergen, K. J., Hoffman, L., \& Anderson, H. (1996). Is Diagnosis a Disaster? A constructionist trialogue. In F. Kaslow (Ed.), Handbook of relational diagnosis and dysfunctional family patterns (pp. 102-118). New York: John Wiley \& Sons.

Grad, F. P. (2002). The preamble of the constitution of the World Health Organization. Bulletin of the World Health Organization, 80(12), 981-984.

Guanaes, C. (2006). A construção da mudança em terapia de grupo: um enfoque construcionista social. São Paulo: Vetor.

Guanaes, C. \& Japur, M. (2001). Grupo de apoio com pacientes psiquiátricos ambulatoriais em contexto institucional: Análise do manejo terapêutico. Psicologia: Reflexão $e$ Crítica, 14(1), 191-199.

Guanaes, C. \& Japur, M. (2005). Sentidos de doença mental em um grupo terapêutico e suas implicações. Psicologia: Teoria e Pesquisa, 21(2), 227-235.

Guedes, A. C., Kantorski, L. P., Pereira, P. M., Clasen, B. N., Lange, C., \& Muniz, R. M. (2010). A mudança nas práticas em saúde mental e a desinstitucionalização: uma revisão integrativa. Revista Eletrônica de Enfermagem, 12(3), 54753.

Guimarães, A. C. C. \& Contel, J. O. B. (2009). Psicoterapia de grupo em hospital-dia psiquiátrico. Paidéia, 19(44), 378-385.

Habigzang, L. F., Hatzenberger, R., Corte, F. D., Stroeher, F., \& Koller, S. (2006). Grupoterapia cognitivo-comportamental para meninas vítimas de abuso sexual: descrição de um modelo de intervenção. Psicologia Clínica, 18(2), 163-182.

Klein, R. H. (1993). Short-term group psychotherapy. In H. I. Kaplan \& B. J. Sadock (Eds.), Comprehensive group psychotherapy (pp. 256-270). Philadelphia: William \& Wilkins.

Ludermir, A. B. (2008). Desigualdades de classe e gênero e saúde mental nas cidades. Physis Revista de Saúde Coletiva, 18(3), 451-467.

Marmot, M. (2005). Social determinants of health inequalities. Lancet, 365, 1099-1104.

McNamee, S. \& Hosking, D. M. (2011). Research and Social Change: a relational constructionist approach. New York/ Oxford: Routledge.

McNamee, S. (2002). The social construction of disorders: From pathology to potential. In J. D. Raskin \& S. K. Bridges (Eds.), Studies in meaning: exploring constructivist psychology (pp. 143-168). New York: Pace University Press.

Patel, V., Lund, C., Hatherill, S., Plagerson, S., Corrigall, J., Funk, M., \& Flisher, A. J. (2010). Mental disorders: Equity and social determinants. In E. Blas \& A. S. Kurup (Eds.), Equity, social determinants and public health programs (pp. 115-158). Geneva, Switzerland: World Health Organization Press.

Pinheiro, C. M., Santos, N. L. D., \& Santos, J. E. D. (2009). Discursos coletivos sobre sofrimento psíquico em famílias em situação de vulnerabilidade social. Saúde em Debate, 33(83), 465-473. 
Rasera, E. F. \& Japur, M. (2007). Grupo como construção social: aproximações entre construcionismo social e terapia de grupo. São Paulo: Vetor.

Sampson, E. E. (1993). Celebrating the other: a dialogical account of human nature. New York: Harvest Wheatsheaf.

Scheidlinger, S. (1994). An overview of nine decades of group psychotherapy. Hospital and Community Psychiatry, 45, 217-225.

Schopler, J. H. \& Galinsky, M. J. (1993). Support groups as open systems: a model for practice and research. Health \& Social Work, 18, 195-207.

Shotter, J. \& Katz, A. M. (1996). Articulating the practice from within the practice itself: establishing formative dialogues by the use of "social poetics". Concepts and Transformation, l(2-3), 213-237.

Yalom, I. D. \& Leszcz, M. (2005). Theory and practice of group psychotherapy ( $5^{\mathrm{a}}$ ed.). New York: Basic Books.

Zioni, F. \& Westphal, M. F. (2007). O enfoque dos determinantes sociais de saúde sob o ponto de vista da teoria social. Saúde e Sociedade, 16(3), 26-34.

Received in: 30/09/2012

Revised in: 01/06/2013

Accepted in: 16/06/2013

Andrezza Gomes Peretti is a psychologist, graduated from the Department of Psychology, Faculty of Philosophy,

Sciences and Letters of Ribeirão Preto, University of São Paulo. Address: Departamento de Psicologia /FFCLRP-

USP. Av. Bandeirantes, 3900. Bairro Monte Alegre. Ribeirão Preto/SP, Brasil. CEP 14040-901. E-mail: andrezza gp@hotmail.com
Pedro Pablo Sampaio Martins is master in Psychology from the Faculty of Philosophy, Sciences and Letters of Ribeirão Preto. He has a bachelor's degree in Psychology from the Federal University of Uberlândia (2010). E-mail: pedropablomartins@gmail.com

Carla Guanaes-Lorenzi is Professor of the Department of Psychology at the Faculty of Philosophy, Sciences and Letters of Ribeirão Preto. She has a master's degree in Psychology from USP (2000), and a doctoral degree in Psychology from USP (2004). She has a major in Marriage and Family Therapy from FAMILIAE Institute. Associate member of The TAOS Institute (http:// www.taosinstitute.net). Coordinator of the Research Group: Psychology, Health and Social Constructionism (Psicologia, Saúde e Construcionismo Social) - CNPq. Co-founder and coordinator of the Laboratory of Research and Study in Group Practices (Laboratório de Pesquisa e Estudo em Práticas Grupais - LAPEPG) of the Department of Psychology at USP/Ribeirão Preto. Address: A/C Carla Guanaes Lorenzi. Universidade de São Paulo. Departamento de Psicologia. Avenida Bandeirantes, 3900. Ribeirão Preto/SP, Brasil. CEP 14090-901. E-mail: carlaguanaes@,ffclrp.usp.br

\section{How to cite this article:}

Peretti, A. G., Martins, P. P. S., \& Guanaes-Lorenzi, C. (2013). The management of social problems talk in a support group. Psicologia \& Sociedade, 25(n. spe.), 101110. 